\title{
Prediksi Pengoperasian Traktor di Lahan Kering Menggunakan Artificial Neural Network
}

\section{Prediction of Tractor Operation in Dry Land Using Artificial Neural Network}

\author{
Taufik Nugraha Agassi, Yose Sebastian, Zainal Arifin \\ Jurusan Teknologi Pertanian, Politeknik Negeri Lampung \\ Jl. Soekarno-Hatta no. 10 Rajabasa-Bandar Lampung 35144
}

\begin{abstract}
Soil water content is an important parameter in making a decision to use a tractor or not. The process of measuring soil water content and levels of field capacity in conventional which takes a long time and cannot be used in real-time to measure it is a major problem in the field. Determinants of soil water content such as ambient temperature, humidity, and rainfall can be obtained easily and quickly either by using a tool or retrieving data from the nearest BMKG station. The objective of this research is to obtain the most optimal prediction model in making decisions about tractor operation in dry land. This research uses an Artificial Neural Network (ANN) in modeling predictions of tractor operation. Prediction of tractor operation is a prediction of tractor use on a certain day using input data obtained before the day of tractor use. ANN modeling uses the back-propagation supervised learning method. The best ANN model used four hidden neurons with a learning coefficient of 0.2, a momentum of 0.8 and 20,000 iterations. This model has been able to provide optimal predictions with an accuracy value of $77 \%$. The ANN model has been successful in predicting tractor operation on dry land using the back-propagation supervised learning method.
\end{abstract}

Keywords: Artificial Neural Network (ANN), prediction of tractor operation, soil water content

Naskah ini diterima pada tanggal 5 Oktober 2020, direvisi pada tanggal 19 Oktober 2020 dan disetujui untuk diterbitkan pada tanggal 15 Desember 2020

\section{PENDAHULUAN}

Pertanian merupakan sektor utama pembangunan Indonesia dalam mewujudkan ketahanan pangan. Kualitas, kuantitas dan kontinuitas produksi merupakan faktor kunci dalam menjaga kestabilan dan ketahanan pangan. Perencanaan dan implementasi mekanisasi pertanian secara benar dan tepat menciptakan efektivitas dan produktivitas pertanian yang berkesinambungan. Pengolahan lahan merupakan faktor utama memperoleh produktivitas yang tinggi dari sektor pertanian. Pengolahan lahan pertanian khususnya pengolahan tanah merupakan salah satu kunci sukses dalam budidaya tanaman. Pengolahan tanah dapat memperbaiki sifat-sifat fisik tanah sehingga dapat menjamin keseimbangan antara air, udara, dan suhu di dalam tanah. Teknologi pengolahan lahan dapat membantu meningkatkan efektivitas pengolahan lahan semisal penggunaan traktor. 
Petani membutuhkan traktor dalam pengolahan lahan untuk meningkatkan produktivitasnya dan intensitas tanam yang berimplikasi kepada meningkatnya produksi. Penggunaan traktor merupakan adopsi teknologi pengolahan tanah. Keadaan tanah sangat menentukan penggunaan dan kinerja traktor (Taghavifar, dkk., 2015). Lokasi lahan yang tergenang air dapat menghambat jalannya traktor. Kadar air tanah merupakan parameter penting dalam pengambilan keputusan untuk menggunakan traktor atau tidak. Hal ini dikarenakan kadar air tanah yang tinggi membuat tanah menjadi lengket, slip roda yang tinggi, serta meyebabkan kerusakan sifat fisik tanah. Kadar air tanah sangat erat kaitannya dengan kadar air kapasitas lapang. Kadar air kapasitas lapang menunjukan kemampuan maksimal tanah dalam menyimpan air (Sulistyono dan Abdillah, 2017). Penentuan nilai kadar air kapasitas lapang dapat menggunakan tiga metode yang berbeda yaitu alhricks, drainase bebas dan pressure plate. Metode alhricks dan drainase bebas memiliki persamaan mendasar yaitu nilai kadar air didasarkan pada hilangnya air gravitasi sedangkan metode pressure plate berdasarkan tekanan (Haridjaja, dkk., 2013). Semua metode ini membutuhkan waktu lebih dari satu hari dalam penentuan kadar air kapasitas lapang.

Kadar air merupakan salah satu karakteristik tanah yang cukup penting peranannya dalam bidang pertanian. Karakteristik suatu sampel tanah banyak berkaitan erat dengan informasi kadar airnya. Pengukuran kadar air secara konvensional dilakukan dengan menggunakan metode gravimetri. Metode ini membutuhkan waktu yang cukup lama dalam menghasilkan nilai kadar air tanah. Selain itu, metode ini juga tidak bisa digunakan secara real-time untuk mengukur kadar air sampel tanah. Saat ini sudah ada teknologi sensor elektromagnetik untuk mengukur kadar air tanah (Soulis dan Elmaloglou, 2018). Spektroskopi sinar gamma proksimal baru-baru ini muncul sebagai teknik yang menjanjikan untuk pemantauan tanpa henti terhadap kadar air tanah (Baldoncini, dkk., 2018). Metode-metode ini membutuhkan biaya yang cukup besar dalam penerapannya.

Ketersediaan air pada pertanian lahan kering hanya mengandalkan air hujan. Hujan yang tidak terjadi setiap hari serta intensitas penyinaran matahari yang tinggi menyebabkan tingginya evapotranspirasi. Suhu lingkungan dan kelembapan lingkungan mempengaruhi laju evapotranspirasi (Nurhayati dan Aminuddin, 2016). Pengaruh evapotranspirasi sangat menentukan nilai kadar air tanah. Fenomena-fenomena ini menjadi landasan dalam memutuskan penggunaan traktor agar terciptanya efisiensi pengolahan lahan.

Pengolah lahan dan petani sangat membutuhkan data kadar air tanah dan kadar air kapasitas lapang dalam mengambil keputusan cepat guna memutuskan penggunaan traktor di lahan kering. Proses pengukuran kadar air dan kadar air kapasitas lapang secara konvensional yang membutuhkan waktu yang cukup lama dan tidak bisa digunakan secara real-time untuk mengukurnya menjadi permasalahan utama di lapangan. Di sisi lain, faktor penentu kadar air tanah seperti suhu lingkungan, kelembapan udara, dan curah hujan dapat diperoleh dengan mudah dan cepat baik menggunakan alat ataupun mengambil data dari stasiun BMKG terdekat. Permasalahan pengambilan keputusan cepat dalam pengoperasian traktor dapat dibuatkan solusinya dengan 128 Volume 12, Nomor 3| Desember 2020:127-181 
memodelkan prediksi pengoperasian traktor melalui model matematis menggunakan Artificial Neural Network (ANN).

Artificial Neural Network (ANN) adalah sebuah model matematis untuk mensimulasikan struktur dan fungsional dari jaringan neural biologis (Taylor, 2017). ANN merupakan metodologi yang sederhana dan cepat dalam menghasilkan prediksi dibandingkan prediksi secara manual yang berkaitan dengan model yang kompleks (Ushada, dkk., 2015). Penggunaan ANN diharapkan dapat memprediksi keputusan penggunaan traktor. Pemodelan prediksi pengoperasian traktor menggunakan ANN dengan masukan berupa data suhu lingkungan, kelembapan udara, curah hujan dan lama penyinaran matahari. Nilai yang diperoleh dapat secara cepat dan tanpa menggunakan proses pengamatan nilai kadar air tanah dan nilai kadar air kapasitas lapang yang membutuhkan waktu lebih dari satu hari pengamatan. Penelitian ini bertujuan untuk memperoleh model prediksi yang paling optimal dalam pengambilan keputusan pengoperasian traktor di lahan kering.

\section{METODE PENELITIAN}

\section{Sumber Data Penelitian}

Penelitian ini menggunakan enam data pengamatan yaitu data kadar air tanah, kadar air kapasitas lapang, suhu lingkungan rata-rata, kelembapan udara rata-rata, curah hujan dan lama penyinaran matahari. Data penelitian diperoleh dari pengamatan langsung di kebun percobaan, laboratorium mekanisasi Pertanian Politeknik Negeri Lampung dan stasiun BMKG Kelas I Bandara Radin Inten II Bandar Lampung. Data kadar air tanah, kadar air kapasitas lapang, suhu lingkungan rata-rata, dan kelembapan udara rata-rata diperoleh melalui penelitian langsung pada lahan uji. Data curah hujan dan lama penyinaran matahari yang digunakan pada penelitian ini diambil dari stasiun BMKG Kelas I Bandara Radin Inten II Bandar Lampung. Pengukuran dan pengamatan data dilakukan di pagi hari setiap harinya diantara jam 7.00 sampai jam 9.00. Seluruh data diambil selama 2 bulan dari bulan Agustus sampai September 2020 dengan total 48 data pengamatan.

\section{Alat dan Bahan}

Peralatan yang digunakan dalam penelitian ini adalah alat pengering (oven), bor tanah diameter $2 \mathrm{~cm}$, alumunium foil, cangkul, timbangan analitik dan hygrometer. Bahan yang digunakan dalam percobaan ini yaitu sampel tanah yang diambil sebanyak enam titik setiap harinya.

\section{Artificial Neural Network}

ANN merupakan metodologi yang sederhana dan cepat dalam menghasilkan prediksi dibandingkan prediksi secara manual yang berkaitan dengan model yang kompleks (Ushada, dkk., 
2015). Dalam ANN, data ekperimental berupa input akan dimasukan ke dalam model untuk menghasilkan hubungan matematis yang menghasilkan output berupa prediksi (Brahimi, dkk., 2019). Pemodelan ANN menggunakan Weka (Waikato Environtment for Knowledge Analysis) yang merupakan tools yang open source.

Weka merupakan aplikasi yang terintegrasi yang berisi impelementasi dari metode-metode data mining mulai dari pemrosesan awal hingga pemodelan data yang memudahkan dalam analisis data (Yadav, dkk., 2014; Adinugroho dan Sari, 2018). WEKA merupakan software yang populer bagi peneliti, akademisi dan para peneliti industri (Naik dan Samant, 2016). ANN memiliki 3 layer neuron yaitu input layer, hidden layer dan output layer. Masing-masing neuron terhubung dengan nilai bobot (Topuz, 2010). Performa ANN yang dibangun dioptimalkan dengan mengatur nilai bobot yang tepat. Hal ini bertujuan untuk mengurangi nilai eror model yang dibangun (Heaton, 2012). Struktur ANN yang digunakan dalam penelitian ini terlihat dalam gambar 1. Input dan output struktur ANN berikut digunakan sebagai acuan pembuatan model prediksi pengoperasian traktor di lahan kering.

Prediksi pengoperasian traktor merupakan prediksi penggunaan traktor di hari tertentu menggunakan data input yang diperoleh sebelum hari penggunaan traktor. Model ini memudahkan pengguna tanpa harus mengukur kadar air tanah dan kadar air kapasitas lapang pada hari penggunaan traktor untuk pengambilan keputusan dalam pengoperasian traktor. Pemodelan ANN menggunakan back-propagation supervised learning method. Pengujian data training dan data uji dalam penelitian ini menggunakan cross validation dengan fold sebesar 3.

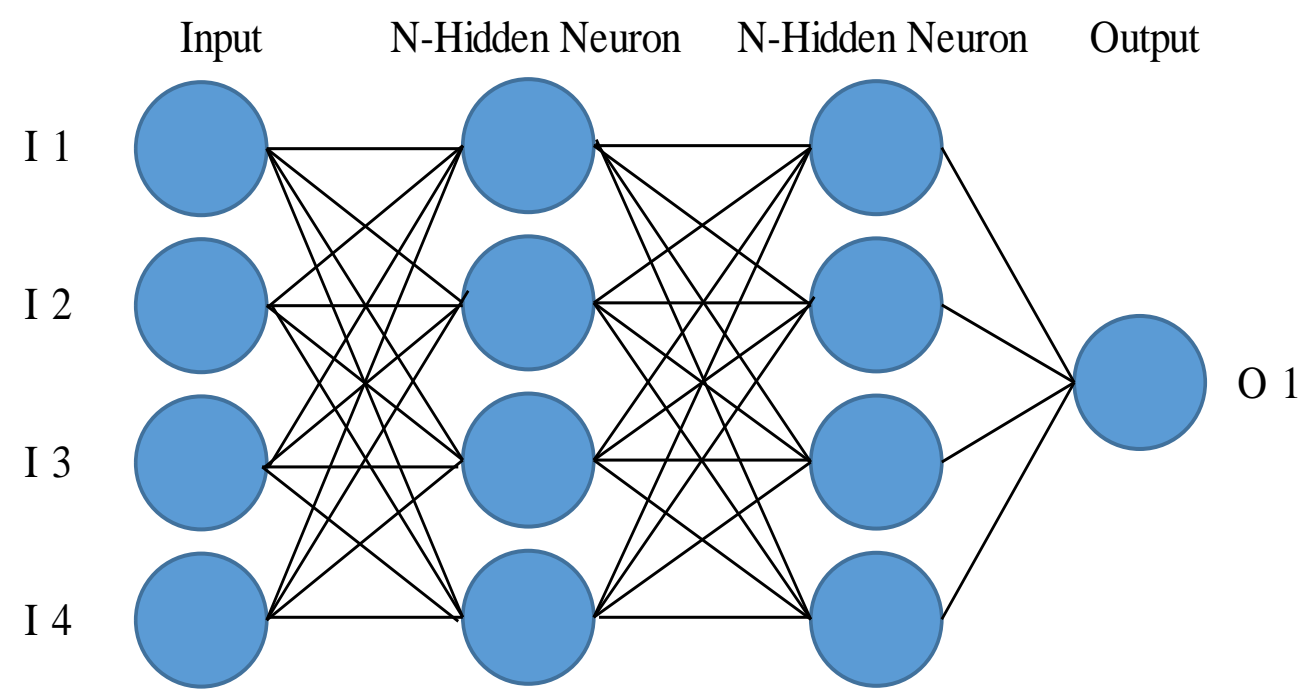

Gambar 1. Struktur ANN Prediksi Pengoperasian Traktor

\section{Keterangan:}

$I_{I}$ : Suhu Lingkungan Rata-rata

$I_{2}$ : Kelembapan Udara Rata-rata

$I_{3}$ : Curah Hujan

$I_{4}$ : Lama Penyinaran Matahari

$O_{1}$ : Keputusan Pengoperasian Traktor

130 Volume 12, Nomor 3| Desember 2020:127-181 


\section{HASIL DAN PEMBAHASAN}

Pengembangan model Artificial Neural Network (ANN) dalam pengambilan keputusan pengoperasian traktor di lahan kering menggunakan empat input yaitu suhu lingkungan, kelembapan udara, curah hujan dan lama penyinaran matahari. Output berupa keputusan pengoperasian traktor berdasarkan perbandingan nilai kadar air tanah dan nilai kadar air kapasitas lapang. Traktor dapat beroperasi saat nilai kadar air tanah berada pada interval nilai kadar air kapasitas lapang. Tabel 1 menunjukkan hasil pemodelan ANN berdasarkan analisis sensitifitas melalui trial and error. Hasil penelitian menunjukkan bahwa model terbaik menggunakan empat hidden neuron dengan learning coefficient sebesar 0,1, momentum sebesar 0,9 dan iterasi sebanyak 20.000 kali. Hal ini ditunjukkan oleh nilai MAE dan RMSE yang terkecil sebesar 0,2515 dan 0,4317. Nilai RMSE selalu lebih besar dibandingkan nilai MAE (Heaton, 2012).

Tabel 1. Analisis Sensitifitas Model ANN

\begin{tabular}{ccccccc}
\hline No & $\begin{array}{c}\text { Hidden } \\
\text { Neuron }\end{array}$ & $\begin{array}{c}\text { Learning } \\
\text { Coefficient }\end{array}$ & Momentum & Iteration & MAE & RMSE \\
\hline 1 & 3 & 0,1 & 0,9 & 10000 & 0,2674 & 0,448 \\
\hline 2 & 3 & 0,1 & 0,9 & 20000 & 0,2672 & 0,4461 \\
\hline 3 & 3 & 0,2 & 0,8 & 10000 & 0,2971 & 0,49 \\
\hline 4 & 3 & 0,2 & 0,8 & 20000 & 0,2972 & 0,4869 \\
\hline 5 & 4 & 0,1 & 0,9 & 10000 & 0,2537 & 0,4345 \\
\hline 6 & 4 & 0,1 & 0,9 & 20000 & 0,2515 & 0,4317 \\
\hline 7 & 4 & 0,2 & 0,8 & 10000 & 0,2541 & 0,4405 \\
\hline 8 & 4 & 0,2 & 0,8 & 20000 & 0,2536 & 0,4381 \\
\hline 9 & 5 & 0,1 & 0,9 & 10000 & 0,2684 & 0,4573 \\
\hline 10 & 5 & 0,1 & 0,9 & 20000 & 0,2623 & 0,4509 \\
\hline 11 & 5 & 0,2 & 0,8 & 10000 & 0,2685 & 0,4816 \\
\hline 12 & 5 & 0,2 & 0,8 & 20000 & 0,2593 & 0,4853 \\
\hline 13 & 6 & 0,1 & 0,9 & 10000 & 0,3094 & 0,5394 \\
\hline 14 & 6 & 0,1 & 0,9 & 20000 & 0,3089 & 0,5396 \\
\hline 15 & 6 & 0,2 & 0,8 & 10000 & 0,3007 & 0,5377 \\
\hline 16 & 6 & 0,2 & 0,8 & 20000 & 0,3233 & 0,5527 \\
\hline 17 & 7 & 0,1 & 0,9 & 10000 & 0,2912 & 0,5342 \\
\hline 18 & 7 & 0,1 & 0,9 & 20000 & 0,2911 & 0,5348 \\
\hline 19 & 7 & 0,2 & 0,8 & 10000 & 0,2879 & 0,5185 \\
\hline 20 & 7 & 0,2 & 0,8 & 20000 & 0,2819 & 0,5131 \\
\hline & & & & & & \\
\hline
\end{tabular}

Tabel 2 menunjukkan evaluasi model ANN berdasarkan terminologi confusion matrix. Hasil penelitian menunjukkan bahwa model terbaik menggunakan empat hidden neuron dengan learning coefficient sebesar 0,2, momentum sebesar 0,8 dan iterasi sebanyak 20.000 kali. Hal ini ditunjukkan oleh nilai presisi dan sensitivitas (recall) yang terbesar yaitu 0,785 dan 0,771 . Nilai 
akurasi dari model ini yaitu 77\%. Model yang paling optimal dan terbaik merupakan model yang memiliki nilai mendekati 1 (Adinugroho dan Sari, 2018). Model ANN telah sukses dalam memprediksi pengoperasian traktor di lahan kering menggunakan back-propagation supervised learning method.

Tabel 2. Evaluasi Model ANN

\begin{tabular}{cccccccc}
\hline No & Model & Precision & Recall & F-Measure & MCC & ROC Area & PRC Area \\
\hline 1 & $3-0,1-0,9-10000$ & 0,734 & 0,729 & 0,731 & 0,4 & 0,785 & 0,796 \\
\hline 2 & $3-0,1-0,9-20000$ & 0,734 & 0,729 & 0,731 & 0,4 & 0,775 & 0,79 \\
\hline 3 & $3-0,2-0,8-10000$ & 0,719 & 0,708 & 0,712 & 0,365 & 0,727 & 0,746 \\
\hline 4 & $3-0,2-0,8-20000$ & 0,719 & 0,708 & 0,712 & 0,365 & 0,716 & 0,747 \\
\hline 5 & $4-0,1-0,9-10000$ & 0,759 & 0,75 & 0,753 & 0,456 & 0,797 & 0,804 \\
\hline 6 & $4-0,1-0,9-20000$ & 0,759 & 0,75 & 0,753 & 0,456 & 0,787 & 0,795 \\
\hline 7 & $4-0,2-0,8-10000$ & 0,759 & 0,75 & 0,753 & 0,456 & 0,801 & 0,811 \\
\hline 8 & $4-0,2-0,8-20000$ & 0,785 & 0,771 & 0,775 & 0,512 & 0,803 & 0,812 \\
\hline 9 & $5-0,1-0,9-10000$ & 0,725 & 0,729 & 0,727 & 0,381 & 0,781 & 0,801 \\
\hline 10 & $5-0,1-0,9-20000$ & 0,775 & 0,771 & 0,772 & 0,493 & 0,789 & 0,808 \\
\hline 11 & $5-0,2-0,8-10000$ & 0,744 & 0,75 & 0,745 & 0,421 & 0,768 & 0,789 \\
\hline 12 & $5-0,2-0,8-20000$ & 0,75 & 0,75 & 0,75 & 0,438 & 0,781 & 0,791 \\
\hline 13 & $6-0,1-0,9-10000$ & 0,675 & 0,688 & 0,678 & 0,265 & 0,732 & 0,763 \\
\hline 14 & $6-0,1-0,9-20000$ & 0,675 & 0,688 & 0,678 & 0,265 & 0,727 & 0,762 \\
\hline 15 & $6-0,2-0,8-10000$ & 0,683 & 0,688 & 0,685 & 0,286 & 0,713 & 0,735 \\
\hline 16 & $6-0,2-0,8-20000$ & 0,648 & 0,667 & 0,653 & 0,204 & 0,695 & 0,72 \\
\hline 17 & $7-0,1-0,9-10000$ & 0,708 & 0,708 & 0,708 & 0,344 & 0,76 & 0,79 \\
\hline 18 & $7-0,1-0,9-20000$ & 0,708 & 0,708 & 0,708 & 0,344 & 0,76 & 0,79 \\
\hline 19 & $7-0,2-0,8-10000$ & 0,708 & 0,708 & 0,708 & 0,344 & 0,76 & 0,78 \\
\hline 20 & $7-0,2-0,8-20000$ & 0,734 & 0,729 & 0,731 & 0,4 & 0,766 & 0,791 \\
\hline & & & & & & & \\
\hline
\end{tabular}

\section{KESIMPULAN}

Model ANN terbaik menggunakan empat hidden neuron dengan learning coefficient sebesar 0,2, momentum sebesar 0,8 dan iterasi sebanyak 20.000 kali. Model ini dapat memberikan prediksi yang optimal dengan nilai akurasi sebesar 77\%. Nilai MAE dan RMSE yang kecil yaitu 0,2536 dan 0,4381 menunjukkan bahwa model ini dapat memprediksi secara baik. Model ANN telah sukses dalam memprediksi pengoperasian traktor di lahan kering menggunakan backpropagation supervised learning method.

\section{UCAPAN TERIMA KASIH}

Kami ucapkan terima kasih yang sedalam-dalamnya kepada Politeknik Negeri Lampung yang telah membiayai penelitian ini di tahun anggaran 2020 dengan nomor 
:193.66/PL15.8/PT/2020. Ucapan terima kasih juga kami sampaikan kepada Laboratorium

Mekanisasi yang telah membantu terlaksananya penelitian ini.

\section{DAFTAR PUSTAKA}

Adinugroho S and Sari Y A. 2018. Implementasi Data Mining Menggunakan WEKA. Malang : UB Press.

Baldoncini M, Albéri M, Bottardi C, Chiarelli E, Raptis K G C, Strati V, dan Mantovani F. 2018. Investigating The Potentialities of Monte Carlo Simulation for Assessing Soil Water Content via Proximal Gamma-Ray Spectroscopy. Journal of Environmental Radioactivity 192 105-116.

Brahimi T, Alhebshi F, Alnabilsi H, Bensenouci A, dan Rahman M. 2019. Prediction of Wind Speed Distribution Using Artificial Neural Network: The Case of Saudi Arabia. Procedia Computer Science 163 41-48.

Haridjaja O, Baskoro D P T, dan Setianingsih M. 2013. Perbedaan Nilai Kadar Air Kapasitas Lapang Berdasarkan Metode Alhricks, Drainase Bebas, dan Pressure Plate Pada Berbagai Tekstur Tanah dan Hubungannya dengan Pertumbuhan Bunga Matahari (Helianthus annuus L.). Jurnal ilmu Tanah dan Lingkungan, 15 52-59.

Heaton J. 2012. Introduction to The Math of Neural Networks. UK : Heaton Research Inc Naik A dan Samant L. 2016. Correlation Review of Classification Algorithm Using Data Mining Tool: Weka, Rapidminer, Tanagra, Orange And Knime. Procedia Computer Science 85662 - 668.

Nurhayati dan Aminuddin J. 2016. Pengaruh Kecepatan Angin Terhadap Evapotranspirasi Berdasarkan Metode Penman Di Kebun Stroberi Purbalingga. Journal of Islamic Science and Technology 2 21-28.

Soulis K X dan Elmaloglou S. 2018. Optimum Soil Water Content Sensors Placement For Surface Drip Irrigation Scheduling In Layered soils. Computers and Electronics in Agriculture 152 1-8.

Sulistyono E dan Abdillah R. 2017. Kadar Air Kapasitas Lapang dan Bobot Jenis Tanah yang Optimal untuk Pertumbuhan dan Produksi Umbi Uwi (Dioscorea alataL). Jurnal Agroekoteknologi AGROVIGOR 10 39-43.

Taghavifar H, Mardani A, dan Hosseinloo A H. 2015. Appraisal of artificial neural networkgenetic algorithm based model for prediction of the power provided by the agricultural tractors. J. Energy 93 1704-1710.

Taylor M. 2017. Neural Networks : A Visual Introduction for Beginners. Canada : Blue Windmill Media.

Topuz A. 2010. Predicting Moisture Content of Agricultural Products Using Artificial Neural Networks. Advances in Engineering Software 41 464-470.

Ushada M, Okayama T, Suyantohadi A, Khuriyati N, dan Murase H. 2015. Daily Worker Evaluation Model for SME-Scale Food Production System using Kansei Engineering and Artificial Neural Network. Agriculture and Agricultural Science Procedia $384-88$.

Yadav A K, Malik H, dan Chandel S S. 2014. Selection Of Most Relevant Input Parameters Using Weka For Artificial Neural Network Based Solar Radiation Prediction Models. Renewable and Sustainable Energy Reviews 31 509-519. 